\title{
Serum-Free Medium Evokes Cyclooxygenase-2 Pathway in A549 Cells
}

\author{
WeiGang Duan*,1, WenHui Chen ${ }^{1}$, Yu Yun ${ }^{2}$, DeQuan Liu², Cheng Luo ${ }^{3}$ and ZhiQiang Shen ${ }^{2}$
}

${ }^{l}$ Key Lab. of Molecular Biology for Sinomedicine, Yunnan University of Traditional Chinese Medicine, 1076, Yuhua Road, University City of Chenggong, Kunming650500, P.R. China; ${ }^{2}$ Yunnan Pharmacological Laboratories of Natural Products, the third affiliated hospital, Kunming Medical College, 191, Western People's Road, Kunming 650031, P.R. China; ${ }^{3}$ Institute of Molecular \& Cell Biology, University of Tartu, Riia St. 23, Tartu 51010, Estonia, EU

\begin{abstract}
Purpose: The main aim of the present study was to find out if serum-free treatment was able to up-regulate cyclooxygenase-2 (COX-2) pathway in A549 cells which were treated with serum-free medium for different hours.

Methods: Prostaglandin $\mathrm{E}_{2}$ ( $\mathrm{PGE}_{2}$, a prostaglandin mainly from COX-2 pathway) in the supernatant synthesized by A549 cells, were determined with $\mathrm{PGE}_{2}$ enzyme immunoassay kits. The protein expression of COX-1, 2 and PGE synthase (PGES) were detected by Western Blotting.

Results: The yield of $\mathrm{PGE}_{2}$ increased when A549 cells were treated with serum-free medium for $12 \mathrm{~h}$, and decreased thereafter. The results of western blotting showed that changes in PGE2 were related to the variation of the expression of COX-2 and PGES.
\end{abstract}

Conclusion: All the results suggested that the COX-2 pathway in A549 cells was up-regulated by serum-free treatment, the mechanism of which was associated with the increase of the expression of COX-2 and PGES.

Keywords: Prostaglandin $\mathrm{E}_{2}$, prostaglandin E synthase, Cyclooxygenase-2, up-regulation, serum-free medium.

\section{INTRODUCTION}

Cyclooxygenase-2 (COX-2), an inducible type of COX, is one of the main enzymes associated with arachidonic acid (AA) metabolism; which is related to inflammation, angiogenesis and carcinogenesis $[1,2]$. The main product of COX-2 pathway is $\mathrm{PGE}_{2}$ : COX-2 transforms arachidonic acid (AA) to $\mathrm{PGH}_{2}$, then, PGE synthase (PGES) transforms it to $\mathrm{PGE}_{2}[3,4]$. The cell line from NSCLC (non-small cell lung cancer), A549 cell is a common tool cell line in studying lung cancer. It was reported that the amount of $\mathrm{PGE}_{2}$ (mainly from COX-2 pathway) in A549 cells was far more than that of 6-keto- $\mathrm{PGF}_{1 \alpha}$ (a metabolite from $\mathrm{PGI}_{2}$, mainly from COX-1 pathway) whether A549 cells were activated by inflammatory stimuli or not [5]. A recent report [5] suggested that the yield of $\mathrm{PGE}_{2}$ in A549 cells was sensitive to serum-free medium. However, there are few further understandings of the new effect. The main aim of the present study was to reveal that serum-free medium was an effective factor to up-regulate COX-2 pathway in A549 cells.

\section{MATERIALS AND METHODS}

\section{Materials}

The cell line A549 cell from American Type Culture Collection (ATCC) was used and the identity of cells was

*Address correspondence to this author at the Key Lab. of Molecular Biology for Sinomedicine, Yunnan University of Traditional Chinese Medicine, 1076, Yuhua Road, University City of Chenggong, Kunming650500, P.R. China; Tel: +86-159-25146965;

Fax:+86-871-5918014; E-mail: deardwg@126.com checked by their typical morphology. $\mathrm{AA}, \mathrm{PGE}_{2}$ enzyme immunoassay (EIA) kits, 6-keto-PGF ${ }_{1 \alpha}$ EIA assay kits, and rabbit anti- cytosolic PGES (human) were purchased from Cayman Chemical Company, Ann Arbor, USA. Rabbit antiCOX-1 (human) antibody, rabbit anti- COX-2 (human) antibody, and goat anti-rabbit antibody linked with horse radish peroxidase were produced by Boster Biological Engineering Co., Ltd., Wuhan, China. Tecan Reader was manufactured by Tecan Group Ltd., Männedorf, Switzerland. Ham's F12K culture media were produced by Hyclone Company of Thermo Fisher Scientific Inc., Logan, USA. Fetal bovine serum was manufactured by Hangzhou Sijiqing Bio-material Co., Ltd., Hangzhou, China. Chemiluminescence kit (Pierce) was produced by Thermo Fisher Scientific Inc., Rockford, USA. Semi-Dry Electrophoretic Transfer Cell, Gel Scanner and its system of "Quantity One" were manufactured by Bio-Rad Laboratories, Inc., Farmington, USA. Other reagents used were of analytic purity made in China.

\section{Cell Culture}

A549 cells were incubated in F12K medium with $2 \mathrm{mM}$ L-glutamine, $1.5 \mathrm{~g} / \mathrm{L}$ sodium bicarbonate and $10 \%$ fetal bovine serum (standard medium), at $37^{\circ} \mathrm{C}$, in an atmosphere of $95 \%$ air and $5 \% \mathrm{CO}_{2}$ [6]. When cells were about to capture $80 \%$ area of the flask, they were digested and seeded to other flasks or to 96- well plates with different treatments.

\section{PGE $_{2}$ Assay and 6-keto-PGF $1 \alpha$ Assay}

The A549 cells seeded in 96- well plates $\left(5 \times 10^{4} / \mathrm{mL}\right)$ were cultured in standard medium for $12 \mathrm{~h}$. After serumstarved for $0,6,12$, or $24 \mathrm{~h}, \mathrm{~A} 549$ cells were exposed to AA of $10 \mu \mathrm{M}$ for $30 \mathrm{~min}$. The supernatant was collected as 
sample. $\mathrm{PGE}_{2}$ was determined with $\mathrm{PGE}_{2}$ EIA kits. The product of 6-keto-PGF $\mathrm{F}_{1 \alpha}$ was determined with 6-keto-PGF $\mathrm{F}_{1 \alpha}$ EIA kits. The cells in every well was lyzed with DMSO and the protein content was determined with Bradford protein assay [7]. The final concentration of $\mathrm{PGE}_{2}$ or $6-$ keto-PGF $1 \alpha$ was normalized to the protein content of the same well.

\section{Western Blotting}

A549 cells seeded in flasks $\left(1 \times 10^{4} / \mathrm{ml}\right)$ were cultured with standard medium at first. When they were about to occupy $50 \%$ area of the flasks, the medium was renewed with serum-free medium and cultured for $0,6,12$, or $24 \mathrm{~h}$. The area captured by A549 cells was less than $80 \%$ of the flask before cells lysing. The cells were lyzed on ice in a lyse buffer containing $20 \mathrm{mM}$ TrisHCl (pH7.5), 0.1\% Triton X100, $1 \mathrm{mM}$ EDTA, $0.2 \mathrm{mM}$ dithiothreitol, and $2 \mathrm{mM} \mathrm{NaF}$. The lysate was spun $(6,000 \times g)$ at $4{ }^{\circ} \mathrm{C}$ for $5 \mathrm{~min}$ and the supernatant was collected as protein sample. The protein in the supernatant was determined with Bradford protein assay [7], and the supernatant was diluted with lyse buffer to a solution containing $2.00 \mathrm{mg} / \mathrm{ml}$ protein.

Different samples of $20.0 \mu \mathrm{g}$ protein were applied for SDS-PAGE (sodium dodecylsulphate - polyacrylamide gel electrophoresis). The protein in SDS-PAGE was transferred to a nitrocellulose (NC) filter by an electrical current of $10 \mathrm{~V}$ for $60 \mathrm{~min}$ in a Semi-DryElectrophoretic Transfer Cell. The filter was blocked with 3\% BSA, stained with primary antibodies and secondary antibodies, and developed with a chemiluminescence kit. The results of western blotting were scanned by the software of "Quantity One" and the relative density was calculated by using Formula 1.

$$
\text { Re lative Density }=\frac{\text { Density of Band of interest }}{\text { Density of Actin Band of the Same Sample }}
$$

(Formula 1)

\section{Statistical Analyses}

Values are expressed as mean \pm S.D. One-way analysis of variance (ANOVA) was performed, and the least significant difference (LSD) method of post hoc test was performed to compare the means with the control group. Statistically significant differences were accepted at $P<0.05$ [6].

\section{RESULTS}

\section{PGE $_{2}$ and 6-keto-PGF $1 \alpha$ from A549 Cells with Serum-} Free Treatment

In order to observe whether serum-free treatment was able to evoke COX-2 pathway, the amount of $\mathrm{PGE}_{2}$ was detected at several intervals over $24 \mathrm{~h}$ (Fig. 1). From 0 to 12 $\mathrm{h}$, the yield of $\mathrm{PGE}_{2}$ increased (Fig. 1). However, it then decreased if A549 cells were treated with serum-free medium for $24 \mathrm{~h}$. The yield of 6 -keto- $\mathrm{PGF}_{1 \alpha}$ remained at a relative stable level of lower concentration (Fig. 1).

\section{COX-2 and PGES Expression Evoked by Serum-Free Medium}

In order to find the direct cause(s) of the COX-2 pathway activation, the expression of both COX-2 and PGES in A549 cells treated with serum-free medium was detected. The results of western blotting showed that, from 0 to $12 \mathrm{~h}$, the expression of COX-2 and PGES increased (Fig. 2A). However, the expression of COX-2 and PGES then decreased if A549 cells were treated with serum-free medium longer (between $12-24 \mathrm{~h}$ ). Unlike COX-2, COX-1 expression almost kept at a stable state over $24 \mathrm{~h}$. The relative density analysis showed in Fig. (2B).

\section{DISCUSSION}

There are at least three types of COX discovered, COX1, COX-2, and COX-3. Therefore, there are at least three COX pathways associated with different physiological functions or pathological functions. Among them, COX-2 was proved to be induced by various stimuli, such as lipopolysaccharide (LPS) [8], phorbol 12-myristate 13acetate (PMA) [9], and cytokines [10]. $\mathrm{PGE}_{2}$ is thought to be one of the key molecules involved in many pathological processes including tumor metastasis, immunosuppression,

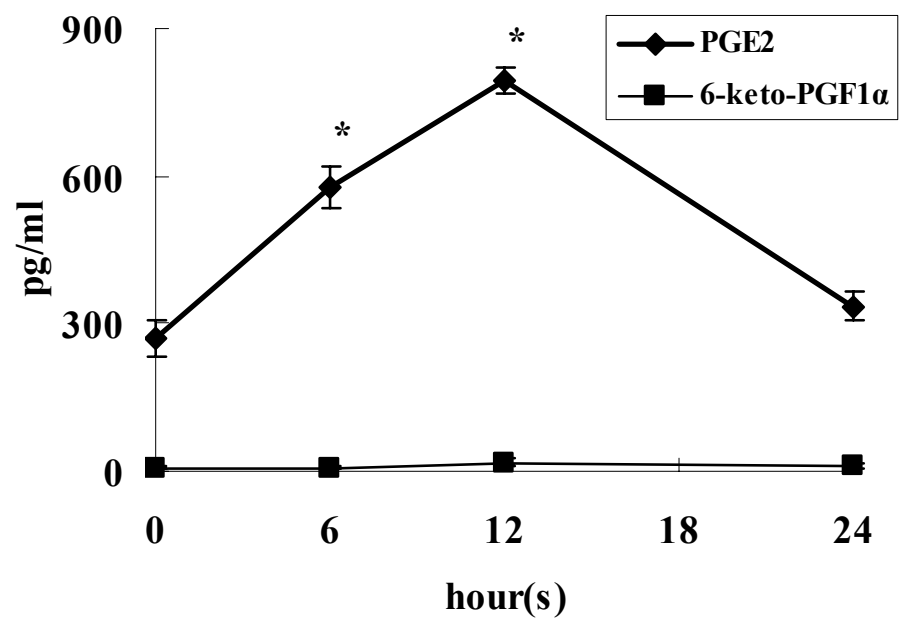

Fig. (1). $\mathrm{PGE}_{2}$ and 6-keto-PGF ${ }_{1 \alpha}$ from $A 549$ cells treated with serum-free medium (Mean \pm S.D., $n=3$ ).

From 0 to $12 \mathrm{~h}$, the yield of $\mathrm{PGE}_{2}$ in $\mathrm{A} 549$ cells increased then decreased if A549 cells treated longer, but 6-keto-PGF ${ }_{1 \alpha}$ remained at a lower stable level. *: $P<0.05$ versus $0 \mathrm{~h}$. 
A

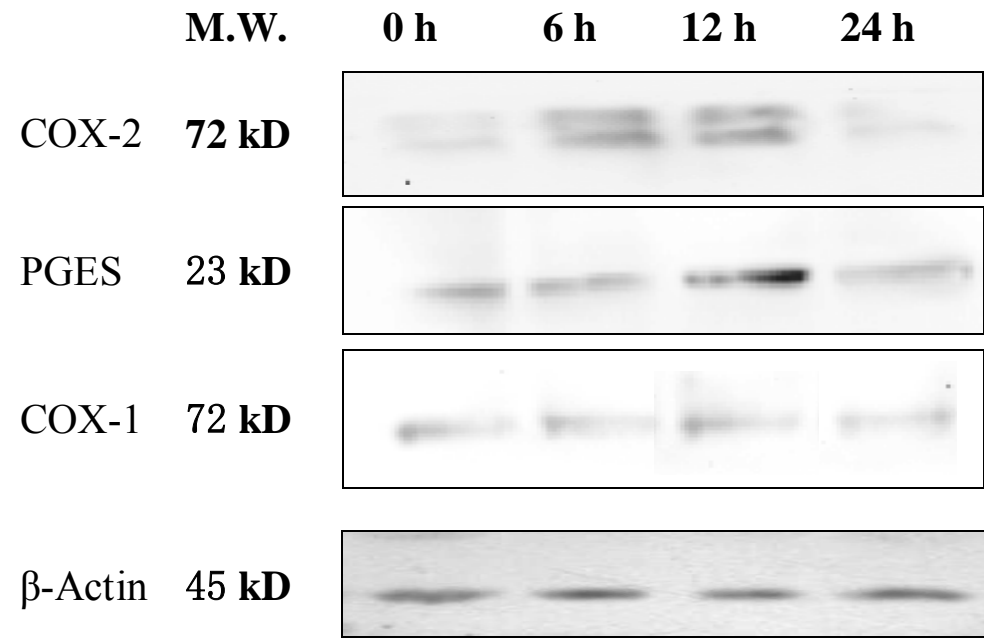

B

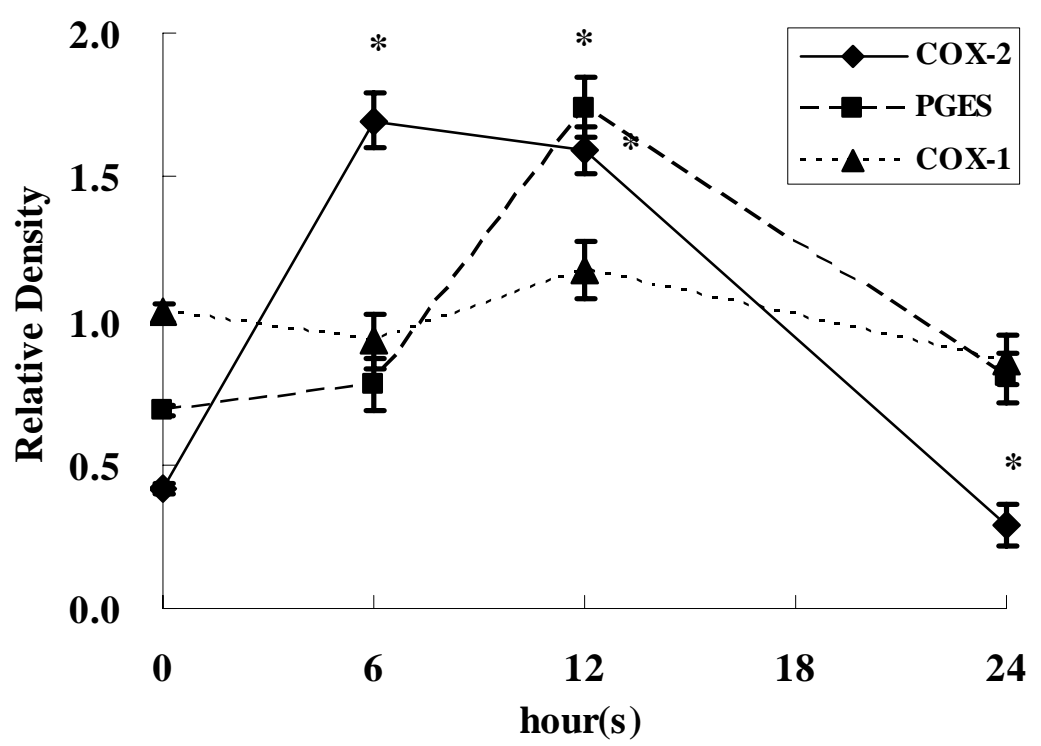

Fig. (2). The expression of COX-2, PGES, and COX-1 in A549 cells treated with serum-free medium.

A549 cells were treated with serum-free medium for $0,6,12$, or $24 \mathrm{~h}$. The results of western blotting (A) showed that the expression of COX-2 and PGES was up-regulated from 0 to $12 \mathrm{~h}$ and down-regulated thereafter; while the expression of COX-1 kept at a relatively stable level all the time. "B" was the result from "A" expressed in relative density (Mean \pm S.D. $n=3, * P<0.05$ versus 0 h).

even hyperplasia [1-4,11]. Recently, Yao and his colleagues [5] established a screening method in A549 cells for nonsteroidal anti-inflammatory drugs (NSAIDs). Their results suggested that COX-2 pathway of A549 cells was inducible by serum-free treatment, but detailed information was unknown. In Yao's study [5], the effect of COX-2 pathway up-regulation caused by serum-free treatment for $12 \mathrm{~h}$ was even greater than that by LPS of $10 \mu \mathrm{g} / \mathrm{ml}$.

The results of the present study showed that serum-free culture medium is able to induce the COX-2 pathway. The COX-2 pathway is the main COX pathway in A549 cells, and is believed to be highly associated with tumorigenesis of NSCLC [10,11]. Apart from LPS, PMA, and some cytokines, the present study first discovered that serum-free treatment was also a powerful stimulus to increase $\mathrm{PGE}_{2}$ in A549 cells; the direct causes of which were serum-free treatment up-regulating the expression of COX-2 and PGES. Since the immediate product of the three types of COX catalyzed from AA was $\mathrm{PGH}_{2}$, the up-regulation of PGES expression is important in ensuring $\mathrm{PGE}_{2}$ increase. PGES is an enzyme at the downstream of COX-2 pathway, and the expression of PGES often couples with that of COX-2 $[12,13]$. Based on the results in the present study, it could be deduced that, the up-regulation of COX-2 expression occurs first, and the up-regulation of PGES expression follows. The results indicted that there is a short lag (about $6 \mathrm{~h}$ ) from 
COX-2 expression up-regulation to PGES expression upregulation. However, how PGES coupled with COX-2 is not thoroughly clear so far. However, if A549 exposed to serumfree medium too long $(24 \mathrm{~h})$, the up-regulation of COX-2 pathway was inhibited; for A549 can be starved to death for too long time in serum-free medium.

Taken together, the present study discovered that COX-2 pathway in A549 cells was able to up-regulated when treated with serum-free medium for $12 \mathrm{~h}$, and the direct mechanism was associated with the activation of the expression of COX2 and PGES. This finding is useful for COX-2 inhibition model and offers new understanding of lung cancer.

\section{REFERENCES}

[1] Grimes KR, Warren GW, Fang F, Xu Y, St Clair WH. Cyclooxygenase-2 inhibitor, nimesulide, improves radiation treatment against non-small cell lung cancer both in vitro and in vivo. Oncol Rep 2006; 4: 771-6.

[2] Tong Z, Wu X, Chen CS, Kehrer JP. Cytotoxicity of a noncyclooxygenase-2 inhibitory derivative of celecoxib in non-smallcell lung cancer A549 cells. Lung Cancer 2006; 1: 117-24.

[3] Taketo MM. Cyclooxygenase-2 inhibitors in tumorigenesis (part I). J Natl Cancer Inst 1998; 20: 1529-36.

[4] Taketo MM. Cyclooxygenase-2 inhibitors in tumorigenesis (Part II). J Natl Cancer Inst 1998; 21: 1609-20.

[5] Yao JC, Duan WG, Yun Y, et al. Screening method for nonsteroidal antiinflammatory drugs based on the cyclooxygenase
2 pathway activated by serum-free stimulation in A549 cells. Yakugaku Zasshi 2007; 3: 527-32.

[6] Duan W, Zhang L. Cyclooxygenase inhibitors not inhibit resting lung cancer A549 cell proliferation. Prostaglandins Leukot Essent Fatty Acids $2006 ; 5: 317-21$.

[7] Zor T, Selinger Z. Linearization of the Bradford protein assay increases its sensitivity: theoretical and experimental studies. Anal Biochem 1996; 2: 302-8

[8] Wu S, Duan S, Zhao S, Cai Y, Chen P, Fang X. Atorvastatin reduces lipopolysaccharide-induced expression of cyclooxygenase2 in human pulmonary epithelial cells. Respir Res 2005; 6: 27.

[9] Chang MS, Chen BC, Yu MT, Sheu JR, Chen TF, Lin CH. Phorbol 12-myristate 13-acetate upregulates cyclooxygenase-2 expression in human pulmonary epithelial cells via Ras, Raf-1, ERK, and NFkappaB, but not p38 MAPK, pathways. Cell Signal 2005; 3: 299310.

[10] Jung YJ, Isaacs JS, Lee S, Trepel J, Neckers L. IL-1beta-mediated up-regulation of HIF-1alpha via an NFkappaB/COX-2 pathway identifies HIF-1 as a critical link between inflammation and oncogenesis. FASEB J 2003; 14: 2115-17.

[11] Pold M, Zhu LX, Sharma S, et al. Cyclooxygenase-2-dependent expression of angiogenic CXC chemokines ENA-78/CXC Ligand (CXCL) 5 and interleukin-8/CXCL8 in human non-small cell lung cancer. Cancer Res 2004; 5: 1853-60.

[12] Catley MC, Chivers JE, Cambridge LM, et al. IL-1beta-dependent activation of NF-kappaB mediates PGE2 release via the expression of cyclooxygenase-2 and microsomal prostaglandin $\mathrm{E}$ synthase. FEBS Lett 2003; 1-3: 75-9.

[13] Kawao N, Nagataki M, Nagasawa K, et al. Signal transduction for proteinase-activated receptor-2-triggered prostaglandin E2 formation in human lung epithelial cells. J Pharmacol Exp Ther 2005; 2: 576-89.

(C) Duan et al.; Licensee Bentham Open.

This is an open access article licensed under the terms of the Creative Commons Attribution Non-Commercial License (http://creativecommons.org/licenses/by-nc/3.0/) which permits unrestricted, non-commercial use, distribution and reproduction in any medium, provided the work is properly cited. 